\title{
A New Heuristic to Solve the One-Warehouse N-Retailer Problem
}

\author{
Beatriz Abdul-Jalbar Betancor* - Anders Segerstedt** - Joaquín Sicilia-Rodriguez* \\ - Andreas Nilsson** \\ *Universidad de La Laguna, Tenerife, Spain \\ ** Luleä University of Technology, Sweden
}

We deal with a multi-echelon inventory system in which one warehouse supplies an item to multiple retailers. Customer demand arrives at each retailer at a constant rate. The retailers replenish their inventories from the warehouse which in turn orders from an outside supplier. It is assumed that shortages are not allowed and lead times are negligible.

These distribution/inventory systems are encountered frequently in practice and have been extensively analyzed in the literature. A survey of related works can be found in Silver et al. (1998), Muckstadt and Roundy (1993), Zipkin (2000), Axsäter (2000) and Abdul-Jalbar (2005). For such systems the form of the optimal replenishment policy can be very complex. For example, it can require that the order quantity at one or more of the locations varies with time even though all relevant demand and cost factors are time-invariant. Thus, many authors have considered the possibility of restricting attention to simpler classes of strategies. Different methods have been proposed to compute effective policies within these classes of strategies. However, most of them are usually difficult to implement in practice.

In this paper we present a new heuristic to compute effective policies which can easily be used in spreadsheet applications. This heuristic is related to the methods in Segerstedt (1999), Nilsson et al. (2004) and Nilsson and Segerstedt (2004) to solve the Economic Lot Scheduling Problem (ELSP) and the Joint Replenishment Problem (JRP). We show that these approaches can be modified to solve the one-warehouse N-retailer problem. In particular, the heuristic consists of an iterative procedure and the main idea is to find a balance between the replenishment and the inventory holding costs at each installation.

It is well-known that the economic order quantity $(E O Q)$ is the order amount which balances the inventory holding cost against the replenishment cost. Regarding the one-warehouse N-retailer problem, it is easy to see that this property also holds. That is, as the ratios between the replenishment and the inventory holding costs for each installation are closer to one the solution becomes better. The heuristic makes used of this property to determine an effective policy for the one-warehouse N-retailer problem.

Finally, we carry out a computational study to compare the performance of the new heuristic with other existing procedures.

Keywords: Supply chain management, two-echelon inventory system, integer-ratio policies AMS Classification: 90B05, 90B30

\section{References}

Abdul-Jalbar, B., 2005. Distribution systems: advances in inventory management, $\mathrm{PhD}$ thesis, University of La Laguna, Tenerife, Spain.

Axsäter, S., 2000. Inventory Control. Kluwer Academic Publishers, Dordrecht.

Muckstadt, J.A. and Roundy, R.O., 1993. Analysis of Multistage Production Systems. Handbooks in OR and MS, vol. 4 , chapter 2.

Nilsson, A., Segerstedt, A. and Van der Sluis, E., 2004. A new iterative heuristic to solve the Joint Replenishment Problem using a spreadsheet technique. To appear in International Journal of Productions Economics.

Nilsson, K. and Segerstedt, 2004. Costs corrections to feasible solutions of Economic Lot Scheduling Problems, Working Paper, Industrial logistics, Luleä University of Technology.

Segerstedt, A., 1999. Lot sizes in a capacity constrained facility with available initial inventories. International Journal of Production Economics 59 (13), 469-475.

Silver, E.A., Pyke, D. and Peterson, R., 1998. Inventory Management and Production Planning and Scheduling, 3rd Edition. Wiley, New York.

Zipkin, P., 2000. Foundations of Inventory Management, McGraw-Hill, New York. 